\title{
ГРАНИЦЫ ТЕЛЕСНОСТИ: ПОНЯТИЕ И ЗНАЧЕНИЕ
}

\section{LIMITS OF CORPORALITY: CONCEPT AND MEANING}

\section{A. Nemtseva}

Summary: The article justifies the application of the theory of social constructivism as a methodological basis for the study of corporality. The author relies on the understanding of corporality as a phenomenon that arose at the junction of the natural and sociocultural dimensions of being, acting in the form of a cultural code that also has symbolic and semantic significance and performs socially significant functions. It is proposed to investigate physicality by determining and theoretically extending the boundaries of its distribution. The process of becoming corporality by «displacement» of its internal and external boundaries is shown, including the role of normative boundaries in the design of corporality. The significance of the boundaries of the phenomenon of «corporality» in the act of its existence was revealed.

Keywords: corporality, limits of corporality, sense, value, social constructivism, body, functions, activity.

\author{
Немцева Анна Владимировна \\ Старший преподаватель, Байкальский \\ государственный университет \\ nanyav@mail.ru
}

Аннотация: В статье обосновано применение теории социального конструктивизма как методологической базы для исследования телесности. Автор отталкивается от понимания телесности как феномена возникшего на стыке природного и социокультурного измерений бытия, выступающего в виде культурного кода, имеющего также символико-смысловое значение и выполняющего социально значимые функции. Предложено исследовать телесность путем теоретического определения и расширения границ ее распространения. Показан процесс становления телесности при помощи «смещения» внутренних и внешних ее границ, в том числе, показана роль нормативных границ в конструировании телесности. Выявлено значение границ феномена «телесность» в акте его существования.

Ключевые слова: телесность, границы телесности, смысл, значение, социальный конструктивизм, тело, функции, деятельность.

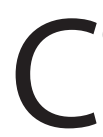

оциально-философский взгляд на проблему человека включает в себя концепции и теории связанные с вопросами его самопознания и саморепрезентации, решение которых связано со стремлением к самосовершенствованию. В этих процессах важная роль отводится телесности. На протяжении развития философской мысли вплоть до середины XX века понятие «телесность» находилось в стадии становления и развития. Рубеж XX-XXI веков явился той точкой отсчета, которую мы можем расценивать как «время рождения» понятия «телесность» в социально-философском ключе, претендующим на статус философской категории. До XX века, можно сказать, самого понятия как такового не существовало, но этот факт никак не отменяет существования феномена телесности. Телесность появилась вместе с человеком, его атрибутами и свойствами, но в философском дискурсе понятие телесности подменялось понятием тела. Иными словами, там, где мыслители прошлого говорили «тело» на самом деле подразумевали телесность. Поэтому, можно сказать, что проблема телесности - это та «вечная» философская проблема, которая всегда привлекала интерес мыслителей различных философских традиций и культурно-исторических эпох.

Так, что же такое телесность? Несмотря на дискуссионность самого вопроса, в современной литературе телесность принято отличать от тела. Под телесностью будем понимать тело, включенное в социокультурную реальность. Этот феномен возникает на стыке природ- ного и социокультурного измерений бытия и выступает в виде культурного кода, имеющего также символикосмысловое значение и выполняющего социально значимые функции. Понятие телесности означает, что человек стремится выйти из рамок собственного тела, осознать себя в мире, в окружении других объектов, в первую очередь нетелесных, и даже противопоставить себя им, то есть телесность мыслится «выше» и «шире» тела как выходящая за его пределы (границы). Поэтому методологическое осмысление проблемы телесности предполагает, прежде всего, выявление границ ее распространения - онтологических, гносеологических, аксиологических, символико-смысловых, праксеологических, психологических, физиологических и пр. Обнаружить границы измерения человеческой телесности в нашей работе представляется возможным, применяя методологию социального конструктивизма. Постановка вопросов о нормативных границах конструирования телесности, об образах и моделях человеческого совершенства, об этической приемлемости «воздействий» на заданную природой «норму» позволяет выйти на новый уровень исследования, анализировать телесность в контексте социокультурного пространства, как элемент устройства общества, составную часть социальных связей. Наиболее плодотворным, на наш взгляд, является изучение телесности как особого типа целостности, характеризующегося подвижными границами, позволяя человеку в той или иной степени «резонировать» с миром. 
Относительная устойчивость границ телесности зависит от «категориального состояния» человека и выступает (осознается) как субъективная точка зрения в интерпретации телесности [1]. Тогда человек мысленно смещает границу телесности, становится способным к выполнению определенных социокультурных функций, в том числе, к проигрыванию социальных ролей. Такое проигрывание является необходимым условием существования человека в социальной действительности, являющейся сложной системой с «сетью» взаимопроникающих подсистем, и во многих из них человек одновременно участвует, исполняя соответственно множество ролей. В зависимости от контекста социального взаимодействия, телесность будет наделяться различными смыслами. Например, для человека, ориентированного на утилитарные ценности, телесность будет существовать и функционировать только в акте утилитарных отношений. Перенос смыслового акцента смещает и границу телесности. Это происходит потому, что для телесности значимым оказывается, конечно, ее содержание, но при этом оно (содержание) достаточно самостоятельно проявляется сквозь форму тела, придавая ей различные коннотации. В первом же случае означающее и означаемое в телесности совпадают, они равны, т.е. означающее есть его означаемое, внешняя форма телесности подчиняет себе ее содержание. На первый взгляд может показаться, что эти границы трудноуловимы и размыты. Граница становится очевидной, пристально начинаем рассматривать тело, а наиболее явной она становится при созерцании внутренних органов. Эта мысль созвучна рассуждениям Г.Г. Шпета о том, что в человеке мы «любим» внешность (имел ввиду кожу), а не всего человека с его внутренними органами, акцентировал внимание на том, что человек без кожи, не был бы для нас привлекательным, даже вызывал бы отвращение.

Немаловажную роль в выявлении границ телесности играют такие характеристики тела, как цвет, запах, симметрия, пропорциональность, форма, размер, вес, ритм пр. Тогда эти свойства становятся значимыми не сами по себе, а как свойства тела, например, цвет тела, звук человеческого голоса и пр. При помощи таких физических проявлений человек способен также сознательно перемещать границу телесности, например, контролируя и регулируя высоту, тон своего голоса, скорость речи и движения. Степень проявления этих свойств зависит от ситуативного контекста социального взаимодействия, которое разворачивается на различных уровнях социальной структуры: статус, возраст, гендер и др. Такие действия, как стояние, сидение, ходьба носят отчетливо видимый социальный характер: человек занимающий, например, высокое социальное положение, сидит и стоит иначе, нежели его подчиненный. Своими способами выражения телесности обладают дети, молодые люди, люди, приближающиеся к зрелости и старости. В этом случае формируются возрастные типы телесности, про- явление которых специфично и обусловлено не только физиологически, но и социально. Каждому типу соответствует определенная техника, зависящая от отношения в обществе к тому или иному возрасту человека. Особенно явно общественный запрос на формирование техники телесности проявляется по отношению к детям. Формируется даже понятие метода «дрессировки» (термин П. Бурдье) детского тела, первым ощущающего на себе воздействие дрессуры $[2,153]$. В этом случае происходит поиск способов сделать более эффективным и более социально удобным существование человека. Выработка типа телесности человека согласно запросам и ценностным установкам общества, - по большому счету, это социальный запрос. При подчинении индивидуального тела коллективным запросам оформляются социальные границы человеческой телесности. Именно здесь тело становится телесностью.

Представление о нормативных границах телесности вырабатывается в ходе развития социума, оно является итогом социальных поисков, отражающихся в правовых актах, этических и эстетических принципах и других социальных реакциях. Кроме того, представления о социальной норме и отклонениях от нее исторически изменчивы и зависят от стереотипов, господствующих в обществе в определенную эпоху.

В процессе «производства» обществом телесности человек «откликается» действиями, направленными на среду, в которую он погружен, - природную и социальную. Разнообразие действий (движений, поступков) в узком смысле можно рассматривать как деятельность, «охватывающую» человека на всех уровнях его сложной структуры. Движения могут выражать не только эмоциональное состояние человека, т.е. возникать совершенно произвольно как выражение страха, ощущения боли, являясь относительно условными и тесно связанными с состояниями тела, но есть движения почти полностью социализированные, - это так называемые семантические движения (классификация И.Э. Коха), которые в известном смысле можно назвать жестами. Семантические движения обозначают утверждения, повеление, просьбу, согласие и т. п., и оказываются тесно связанными с духовной, сознательной стороной бытия человека [3]. К разновидностям движения И.П. Павлов относил речевую деятельность, которая представлена в виде рече-двигательной координации, голоса (процесс произношения звуков). Соединение речи и движения есть взаимоопределяющая функциональная связь духа и тела, социального и биологического начал в человеке.

Деятельный (действующий) человек имеет своеобразный центр, вокруг которого концентрируется вся его деятельность, - это его лицо. Именно лицо является не только эстетическим объектом, но соединяет в себе телесность и духовность: оно способно выражать как 
физиологические, так и экзистенциальные состояния человека: самую глубокую задумчивость, твердую убежденность или мучительное сомнение. Лицо можно считать «центром» телесности еще и по тому, что оно всегда открыто как инструмент общения. Само тело (другие его части) функционируют в более узком диапазоне и открываются в определенных ситуациях, например, граница телесности может быть сдвинута, если общение приобретает эмоционально-чувственный или интимный характер.

В таких ситуациях (случаях) отношения выстраиваются на базе самоочевидных ожиданий, когда люди (участники общения) самой обстановкой уже настраиваются на повышенную эмоциональность или готовятся к другим сценариям взаимодействия. О том, что происходит в случае несоответствия ожиданиям, нацеленных на сознательное разрушение нормального хода социального взаимодействия, можно обратиться к экспериментам Г. Гарфинкеля («Гарфинкелинги») [4]. В ситуациях, не имеющих отношения к чувственным или интимным, граница телесности отодвигается и регулируется не только при помощи социальной дистанции, но и предметов, с которыми человек имеет дело. По мысли Ж.-П. Сартра, тело простирается всегда через предмет, который оно использует. Например, самовосприятие человека, понимание им себя как личности и как существа общественного, даже его статус в коллективе во многом зависят от таких тривиальных вещей, как одежда, аксессуары, предметы быта.

В этом отношении одним из важнейших социокультурных феноменов является одежда. Она представляет собой внешнее проявление телесности, связывающее человеческое тело с окружающей средой и выполняющее такие функции, которыми не обладает тело человека как организм. К числу таких функций следует отнести адаптивную, в соответствии с которой одежда выступает как механизм защиты от воздействия агрессивной окружающей среды, и функцию идентификации, то есть определённое позиционирование себя человеком с помощью одежды, использование одежды как символа социальной роли (статуса) человека.

Функция идентификации проявляется по-разному. С помощью одежды человек сообщает социуму о своем гендере, о социальной роли, о материальном достатке. Одежда может указывать на политический ранг, профессию, возраст и прочее, а также служить социокультурной локализации. Одежду могут замещать другие способы маркировки, например, татуировка, пирсинг, прическа.

Функция суверенизации заключается в наглядной демаркации между «моим» и «не-моим», «тайным» и «явным», когда одежда являет границу приватности, отмечает пределы персональной суверенности. Одежда может выполнять также функцию манипуляции, если она понимается как инструмент приобретения власти и как ее орудие [5].

Отсюда следует, что одежда отвечает всем характеристикам телесности. Она выступает как своеобразная «часть» человека, как его продолжение и дополнительное оформление. Она является социальным регулятором и имеет огромный спектр возможностей, даже можно сказать открывает этот спектр для тела. Одежда способна подчеркивать «категориальное состояние» человека. Она может быть функционально строгой, пышной, стильной и пр., она хорошо вписывается в общую категориально-телесную динамику человека, так как человек в большинстве случаев функционирует в неразрывном единстве с одеждой. А устойчивое в русской культуре выражение о том, что кто-то хорошо или плохо одевается отсылает нас к пониманию, что одежда (одевание) может считаться особой разновидностью деятельности.

Таким образом, можно считать, что деятельность человека выполняет роль связующего звена, объединяющего биологическое и социальное начала в человеке, образуя целостное единство данных начал, но сохраняться это единство будет при условии изменчивости и подвижности границ телесности. Телесность формируется в двух направлениях: внешне - с помощью установления собственных телесных границ в рамках социума, и внутренне - регулировкой экзистенциального вектора личности. Телесность исторически смысливается как понятие, не имеющее изначальной формы и зависящее от общества, которое в рамках той или иной культуры, эпохи, ценностной системы диктует, каким образом должна выглядеть телесность. Формированию телесности при этом служат разнообразные техники, инструменты, знание, власть и иные социокультурные феномены, в которых запечатлевается культура использования тела первого и наиболее естественного инструмента человека. Сама же телесность есть социальный конструкт, обладающий социальной подвижностью. Границы телесности выстраиваются в координации с предметами, которые не являются «мной» (моим телом), что полностью соответствует теории социального конструктивизма. 
2. Бурдье П. Практический смысл / пер. с фр. К.Д. Вознесенская. - М., 1997.

3. Кох И.Э. Основы сценического движения. Л.: Искусство. 1970. -566 с.

4. Гарфинкель Г. Исследования по этнометодологии. - СПб.: Питер, 2007. - 335 с.

5. Аванесов С.С. Тело, одежда, власть / С.С. Аванесов //Конструирование человека: сборник трудов 4-й Всероссийской научной конференции с международным участием: В 2 т. Т.1. - Томск: Издательство Томского государственного педагогического университета, 2011. - 400 c.

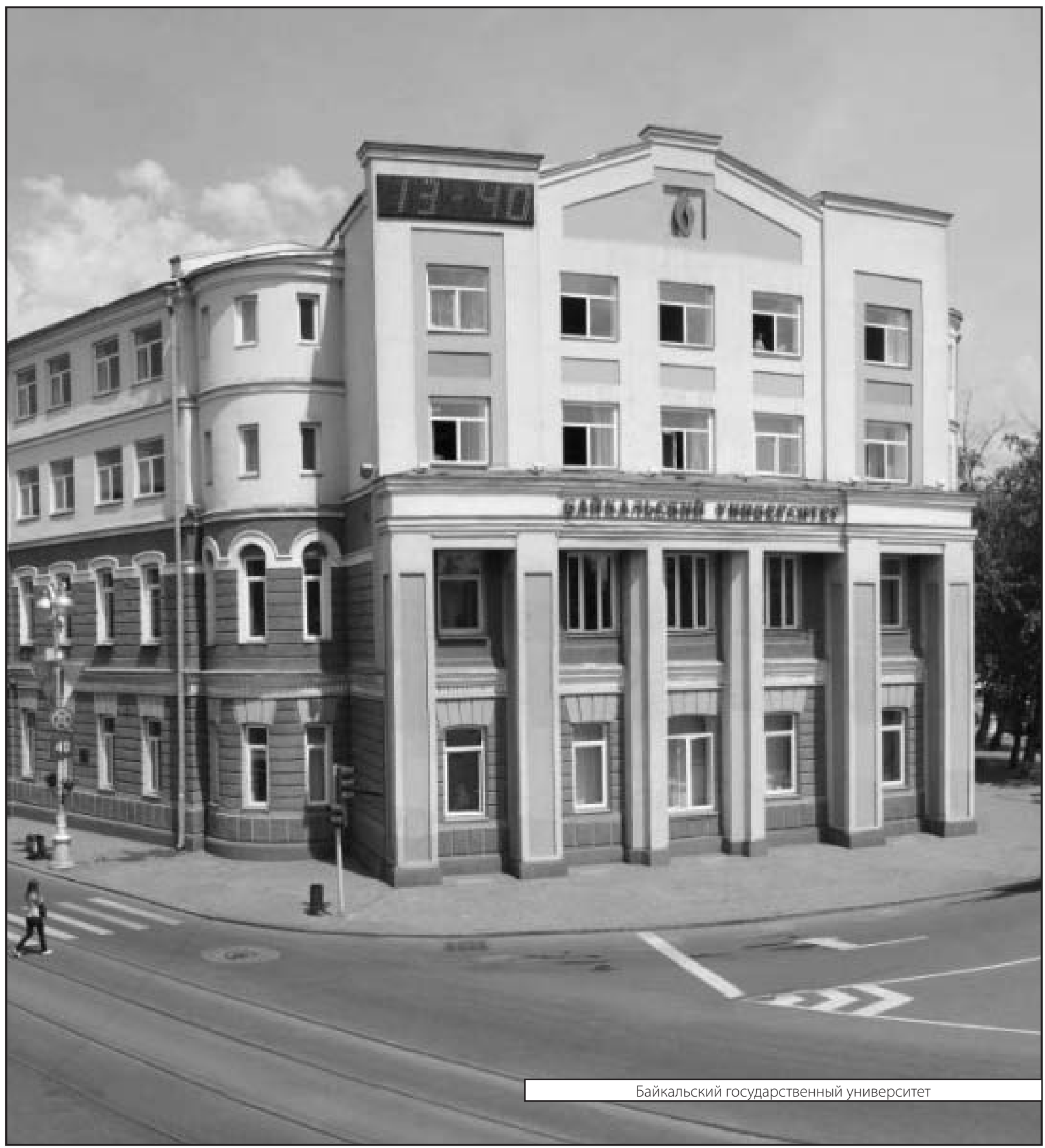

